\title{
Elaboration of Nano Titania-Magnetic Reduced Graphene Oxide for Degradation of Tartrazine Dye in Aqueous Solution
}

Amr A. Nada ${ }^{1,2 *}$, Hesham R. Tantawy ${ }^{3}$, Mohamed A. Elsayed ${ }^{3}$, Mikhael Bechelany ${ }^{1}$ and Mohamed E. Elmowafy ${ }^{3}$

${ }^{1}$ Institut Européen des Membranes, IEM - UMR 5635, ENSCM, CNRS, Univ Montpellier, Montpellier, France.

${ }^{2}$ Dept. of Analysis and Evaluation, Egyptian Petroleum Research Institute, Cairo, Nasr city P.B. 11727, Egypt.

${ }^{3}$ Chemical Engineering Department, Military Technical College, Cairo, Egypt Corresponding authors: amr.nada@umontpellier.fr \& chem amr@yahoo.com

\begin{abstract}
In this paper, magnetic nanocomposites are synthesized by loading reduced graphene oxide (RG) with two components of nanoparticles consisting of titanium dioxide $\left(\mathrm{TiO}_{2}\right)$ and magnetite $\left(\mathrm{Fe}_{3} \mathrm{O}_{4}\right)$ with varying amounts. The structural and magnetic features of the prepared composite photocatalysts were investigated by powder X-ray diffraction (XRD), Fourier transform infrared spectra (FT-IR), transmission electron microscopy (TEM), UV-vis diffuse reflectance spectra (UVvis/DRS), Raman and vibrating sample magnetometer (VSM). The resulting
\end{abstract}


$\mathrm{TiO}_{2} /$ magnetite reduced graphene oxide (MRGT) composite demonstrated intrinsic visible light photocatalytic activity, on degradation of tartrazine (TZ) dye from a synthetic aqueous solution. Specifically, it exhibits higher photocatalytic activity than magnetite reduced graphene oxide (MRG) and $\mathrm{TiO}_{2}$ nanoparticles. The photocatalytic degradation of $\mathrm{TZ}$ dye when using $\mathrm{MRG}$ and $\mathrm{TiO}_{2}$ for $3 \mathrm{~h}$ under visible light was $35 \%$ and $10 \%$ respectively, whereas for MRGT it was more than 95\%. The higher photocatalytic efficiency of MRGT is due to the existence of reduced graphene oxide and magnetite which enhances the photocatalytic efficiency of the composite in visible light towards the degradation of harmful soluble azo dye (tartrazine).

Keywords: titanium dioxide $\left(\mathrm{TiO}_{2}\right)$, magnetite $\left(\mathrm{Fe}_{3} \mathrm{O}_{4}\right)$, graphene titanate, photodegradation, and tartrazine

\section{Introduction:}

Water contamination has become one of the dominant problems in everyday life. One of these problems is the increase of manufacturing wastewater from materials, foods, medicines, etc. which containing various kinds of dyes [1]. These dyes can make environmental problems, in addition to influence the human life as the greater part of them are cancer-causing and mutagenic [2]. The reports demonstrate 
that it is approximately $15 \%$ of the dyes is missed in the effluent during dyeing procedure [3]. These dyes have been considered as non-oxidizable by traditional physical and biological remediation because of their complex molecular structure and their large size molecules. So, their degradation has been deemed as an essential procedures in wastewater treatment [4]. One of these unwholesome dyes is tartrazine dye $(\mathrm{FD} \& \mathrm{C}$ Yellow No. 5, EEC Number $=\mathrm{E} 102, \mathrm{CI}$ Number $=$ 19140) which has the following chemical structure [trisodium 5-hydroxy-1-(4sulfonatophenyl)- 4-(4sulfonatophenylazo)-H-pyrazol-3- carboxylate $] \quad[5,6]$. Tartrazine dye is a water-soluble powder which has been greatly used in nutrition products, medicines, and cosmetics [7-9]. The permissible daily intake for workers exposed occupationally to tartrazine is $0-7.5 \mathrm{mg} / \mathrm{kg}$ body mass [10]. Tartrazine has been classified as a dangerous azo dye because it catalyzes ADHD syndrome, asthma, migraine and thyroid cancer, and other reactions that include blurred vision, itching, purpura, eczema, mutogenetics, and carcinogenetic [11] It is necessary to develop highly effective and sensitive techniques to remove pollutants from water. Recently, heterogeneous photocatalytic oxidation has been confirmed to be an effective technology for degradation of organic contaminants at ambient conditions [12]. Its advantage was the complete degradation of organic pollutants compared with the other water purification techniques [13]. In this technique, photogenerated charge carriers in a semiconductor have been allowed 
the creation of extremely reactive chemical species like hydroxyl radicals. These radicals could mineralize a wide range of organic contaminants rapidly and nonselectively $[14,15]$.

The most usually utilized photocatalyst is $\mathrm{TiO}_{2}$, which has been utilized as promising photocatalyst for the degradation of organic molecules from wastewater. It has distinctive properties like high stability, low toxicity and low cost [16]. However, the photocatalytic efficiency of $\mathrm{TiO}_{2}$ has been restricted for the following reasons: (i) the recombination rate of electron-hole within the $\mathrm{TiO}_{2}$ particles is pretty high which has been required for the time scale of the redox reaction; and (ii) it has wide band gap, and can be excited only by $4 \%$ to $5 \%$ of the sunlight (UV irradiation) $[17,18]$.

The method used to overcome the wide band gap of $\mathrm{TiO}_{2}$, is the tuning of the electronic band structure of the $\mathrm{TiO}_{2}$. This modification has been achieved by chemical reaction using two approaches: (i) incorporation of substances considered as a source of charge-carrier traps and (ii) added materials that decrease the recombination rate between electrons and holes $[19,20]$.

Carbon materials such as graphene and reduced graphene oxide (RG) is an attractive material in many research fields such as lithium-ion battery, nanosensors and energy storage applications owing to its unique properties such as high surface area, electrical conductivity and high mechanical properties [21-27]. 
It also has brilliant mobility of charge carriers and noble thermal conductivity [28]. These properties have been made graphene a very desirable support for semiconductor and metal nanoparticles.

The incorporation of graphene (RG) into $\mathrm{TiO}_{2}$ will be given several advantages such as: (i) increasing adsorptivity: Graphene will be displayed particularly worthy adsorptive properties; (ii) Enhancement visible light absorption: The chemical bonds of Ti-O-C will be provided a red shift in the photo-responding range and facilitate an extra efficient utilization of visible light for the catalyst and (iii) Inhibition of charge recombination [29].

In the other hand, magnetic separation technology has been provided a suitable method for eliminating and recycling magnetic particles/composites by applying suitable magnetic field. $\mathrm{Fe}_{3} \mathrm{O}_{4}(\mathrm{M})$ nanoparticles with a fast and efficient magnetic response can allow the separation of catalysts from reaction mixture without any problem and with high efficiently [30].

In this work, the photocatalytic activity of $\mathrm{TiO}_{2} /$ magnetite reduced graphene oxide (MRGT) composite photocatalysts have been exploited for the photodegradation of a model organic dye tartrazine (TZ) in a suspension system. The main target in this study has been to enhance the photocatalytic properties of the prepared materials to the removal of organic contaminants in water under visible light without any secondary pollution. 


\section{2- Experimental}

\subsection{Materials}

Graphite powder 99.5 wt. \% (332461), Ammonia solution 30\% w/v (1.05423), titanium (IV) isopropoxide (205273), isopropyl alcohol 99.5 wt. \% (278475), Ferric chloride 99 wt. \% (31232), Sodium nitrate 99 wt. \% (229938), Potassium permanganate 98 wt. \% (60459), Sulfuric acid 99.9\% w/v (339741), Hydrogen peroxide 35\% w/v (95321), Ferrous Sulfate 99 wt. \% (F8263) and tartrazine (T0388) were purchased from Sigma Aldrich. All purchased compounds are used as received, with no further purification.

\subsection{Synthesis of graphene oxide (GO)}

Graphene oxide was synthesized using Hummer method with graphite powder as starting material. The GO preparation is described by the following procedure: graphite $(5 \mathrm{~g})$, sodium nitrate $\left(\mathrm{NaNO}_{3}, 2.50 \mathrm{~g}\right)$ and concentrated sulfuric acid $\left(\mathrm{H}_{2} \mathrm{SO}_{4}, 115 \mathrm{ml}\right)$ were added into a $2 \mathrm{~L}$ beaker under stirring for $10 \mathrm{~min}$. At that point, potassium permanganate $\left(\mathrm{KMnO}_{4}, 15 \mathrm{~g}\right)$ was gradually added into the beaker to inhibit any severe reaction that might be happened. The mixture was kept under stirring for $1 \mathrm{~h}$ and then the mixture was kept under stirring in room temperature (at $35^{\circ} \mathrm{C}$ ) for $24 \mathrm{hrs}$. After that, distilled water $(230 \mathrm{ml})$ was added to 
the mixture and as result of the hydration heat, the temperature expanded to $98^{\circ} \mathrm{C}$. The mixture was kept at this temperature for 30 min under stirring. The reaction was then ended by adding distilled water $(700 \mathrm{ml})$ and hydrogen peroxide (30\%, $300 \mathrm{ml}$ ). The obtained product had a brown /yellowish color. It was washed three times with distilled water to remove any remnant ions in the solution. After that, GO was isolated by vacuum filtration from the solution and dried in oven at $60{ }^{\circ} \mathrm{C}$ for $12 \mathrm{hrs}[31]$.

\subsection{Synthesis of magnetite reduced graphene oxide (MRG) composite}

MRG were prepared by in-situ chemical co-precipitation method. First, ferrous sulfate $\left(\mathrm{FeSO}_{4}\right)$ is added to ferric chloride $\left(\mathrm{FeCl}_{3}\right)$ by 1:2 molar ratio. The mixture is added to $80 \mathrm{ml}$ of distilled water under mechanical stirring in existence of $\mathrm{N}_{2}$ gas for $30 \mathrm{~min}$. Then the solution was heated to $70{ }^{\circ} \mathrm{C}$ and kept under stirring for another $30 \mathrm{~min}$. Different amount ratios of GO (10, 20 and 30 wt. \%) relative to magnetite were suspended in $50 \mathrm{~mL}$ of distilled water by ultrasonic treatment for 15 min. Each ratio of GO solution was added to the mixture of iron solution separately to prepare (MRG10, 20 and 30) and the whole mixture was kept under stirring for another $10 \mathrm{~min}$. Ammonia solution $(30 \% \mathrm{w} / \mathrm{v})$ was then added to the mixture until the $\mathrm{pH}$ mixture reaches a value of 10 . Moreover, sodium borohydride was added to the solution under mechanical stirring for $10 \mathrm{~min}$ in ordered to allow 
the reduction of GO nanoparticle and to obtain reduced graphene oxide. The sample was separated by vacuum filtration from the solution and washed with distilled water and ethanol two times respectively, and finally dried in the furnace at $60^{\circ} \mathrm{C}$ for $12 \mathrm{~h} .[32]$

\subsection{Synthesis of $\mathrm{TiO}_{2}$ nanoparticles}

$\mathrm{TiO}_{2}$ nanoparticles were synthesized by hydrolysis method using the following procedure: $7 \mathrm{ml}$ of Titanium (IV) isopropoxide Ti $\left[\mathrm{OCH}\left(\mathrm{CH}_{3}\right)_{2}\right]_{4}$ was dissolved in $100 \mathrm{ml}$ of isopropyl alcohol $\left(\left(\mathrm{CH}_{3}\right)_{2} \mathrm{CHOH}\right)$ and the solution was kept under stirring for $1 \mathrm{~h}$ at room temperature. After that, $400 \mathrm{ml}$ of distilled water was added abruptly to the mixture. The obtained solution was stirred for another $3 \mathrm{~h}$ at room temperature. The sample was filtrated by vacuum filtration from the solution and washed with distilled water and ethanol three times respectively. The obtained sample was dried at $40^{\circ} \mathrm{C}$ in the oven for $6 \mathrm{hr}$. The synthesis process was then finished by calcinating the precipitated particles at $400^{\circ} \mathrm{C}$ for $2 \mathrm{~h}$ in air [33].

\subsection{Synthesis of $\mathrm{TiO}_{2} / \mathrm{MRG}$ composite}

The MRGT composites (25, 50 and 75$)$ were prepared with a weight ratio (3:1, 1:1 and 1:3) respectively between the optimum sample of MRG (MRG20) and $\mathrm{TiO}_{2}$ nanoparticles. $\mathrm{TiO}_{2}$ nanoparticles and MRG 20 were suspended in $50 \mathrm{ml}$ of ethanol 
by ultrasonic treatment for $10 \mathrm{~min}$. The two solutions were mixed together by ultrasonic treatment for $10 \mathrm{~min}$. After that, the sample was separated by vacuum filtration from the solution and it was put in the oven at $60^{\circ} \mathrm{C}$.

\subsection{Characterization}

The phases of the designed nanomaterials were exanimated via an X-ray diffractometer (XRD, Shimadzu XD-1) with a $\mathrm{Cu} \mathrm{K} \alpha$ radiation at $40 \mathrm{kV}$ and 30 $\mathrm{mA}$ over the $2 \theta$ range of $4-80^{\circ}$ at a scanning speed of $4 \% \mathrm{~min}$ with a sampling angle interval of $0.04^{\circ}$. Function groups and bonds are identified using FTIR spectrometer PerkinElmer (model spectrum one FTIR spectrometer, USA). Spectra were recorded between 4000 and $500 \mathrm{~cm}^{-1}$ using standard $\mathrm{KBr}$ pellet. In addition to FTIR, Raman test was carried out using the dispersive Raman microscope (Model Sentera, Bruker, Germany) instrument at laser wave length of $532 \mathrm{~nm}$. Morphology and particle size were determined by high resolution transmission electron microscope (TEM-JEOL JEM 2100) and composition was analyzed by Energy dispersive X-ray spectroscope (EDX) associated with TEM device. Magnetic measurements were carried out at room temperature using a vibrating sample magnetometer (VSM, 735VSM, Model7410; Lake Shore, Westerville, Ohio, USA) with a maximum magnetic field of $31 \mathrm{kOe}$. UV-VIS/DRs spectra 
were recorded using Jasco V 530 spectrometer (Japan) equipped with the integrating sphere accessory for diffuse reflectance spectra.

\subsection{Photocatalytic activity}

To check the photocatalytic activity of MRG and MRGT composites, a reaction of TZ solved in water is performed under simulated visible illumination of a halogen lamp (500W). First, composites were added to $60 \mathrm{~mL}$ of aqueous $\mathrm{TZ}$ solution with concentration of $50 \mathrm{ppm}$. The mixture was under stirring for $30 \mathrm{~min}$ in dark box, until adsorption-desorption equilibrium is obtained between $\mathrm{TZ}$ dye and photocatalyst (composite). The suspension is irradiated as a function of time. Samples are then withdrawn regularly from the reactor and the photocatalyst is separated by an external magnet. The clean transparent solution is analyzed by agilent technologies cary $60 \mathrm{UV}-\mathrm{Vis}$ spectroscopy.

\section{Results and discussions}

Magnetite was loaded with different ratios on reduced graphene oxide. Then various amounts of $\mathrm{TiO}_{2}$ nanoparticles was added to form the MRGTx composites. X-ray diffraction (XRD) was employed first for analysing the crystalline phase of the magnetic reduced graphene nanocomposites (MRGx). Figure (1a) shows the diffraction peaks at $2 \theta$ of $30.27,35.75,43.6,53.73,57.5$, and 63.1 which are 
related to a lattice planes of cubic $\mathrm{Fe}_{3} \mathrm{O}_{4}$ [ (220), (311), (400), (422), (511) and (440)] respectively. The peaks of reduced graphene oxide were not observed for 2 different reasons. Firstly, the magnetite reduced the aggregation of graphene sheets and secondly, the strong signal of iron oxides has tendency to dominate the weak peak of graphene [34].

Crystal structure of magnetic reduced graphene with different amounts of $\mathrm{TiO}_{2} 25$, 50 and $75 \%$ (MRGTx) samples are presented in Figure (1b). In addition to the magnetite peaks, the diffraction peaks at $25.3^{\circ}, 37.8^{\circ}, 48^{\circ}, 54^{\circ}, 55.2^{\circ}$ are observed and are attributed to (101), (004), (200), (105) and (211) crystallographic planes of anatase phases of $\mathrm{TiO}_{2}$ (JCPDS 21-1272). The reflection of $\mathrm{RG}$ is not seen in the XRD patterns of MRGT composites, because the distinctive peak of RG at $24.5^{\circ}$ might be covered by the fundamental peak of anatase $\mathrm{TiO}_{2}$ at 25.3 [35].

Composites were also characterized by Raman. As shown in Figure (2a), the primary components in the Raman spectra of graphitic carbon-based materials are the $\mathrm{G}$ and $\mathrm{D}$ bands. The normal features in Raman spectra were the $\mathrm{D}$ band situated at $1345 \mathrm{~cm}^{-1}$ and the $\mathrm{G}$ band at $1592 \mathrm{~cm}^{-1}$. The $\mathrm{G}$ peak matches to the optical $\mathrm{E}_{2 \mathrm{~g}}$ phonons at the Brillouin zone center which outcome from the bond stretching of $\mathrm{sp}^{2}$ carbon pairs in both, rings and chains. The $\mathrm{D}$ peak demonstrates breathing mode of aromatic rings which grow due to the defect in the sample. The D peak intensity is usually utilized as a measure of the level of disorder. The shift and the 
shape of the overtone of the $\mathrm{D}$ peak, called as $2 \mathrm{D}$ peak around $2680 \mathrm{~cm}^{-1}$, can be related to the quantity of graphene layers $(\mathrm{N})$ [36].

In Raman spectrum of MRGx (where $\mathrm{x}$ is 10, 20 and 30), there are three peaks situated at $217,272,367 \mathrm{~cm}^{-1}$, which are related to $\mathrm{Fe}_{3} \mathrm{O}_{4}$ nanoparticles as show in Figure (2b). The wide peaks showed at $1357 \mathrm{~cm}^{-1}$ and $1592 \mathrm{~cm}^{-1}$ are related to the $D$ and $G$ groups of reduced graphene oxide, respectively [37]. The $I_{D} / I_{G}$ ratio in Go is 0.97. In MRG10, MRG20 and MRG30, the two distinctive peaks of G and D bands still coexist, however $\mathrm{I}_{\mathrm{D}} / \mathrm{I}_{\mathrm{G}}$ ratios are $1.52,1.14$ and 1.09 respectively. The relatively high intensity of the D band when compared to the $\mathrm{G}$ band of composites indicates the presence of $\mathrm{sp}^{3}$ defects within $\mathrm{sp}^{2}$ during the functionalization of graphene by magnetite and the high exfoliation of rGO layers. This confirming that, a chemical bonding between $\mathrm{Fe}_{3} \mathrm{O}_{4}$ and $\mathrm{rGO}$ was created from the replacement of oxygen in $\mathrm{GO}$ by $\mathrm{Fe}_{3} \mathrm{O}_{4}$ during reduction as well as the efficient exfoliation of graphene [38].

Raman spectrum of MRGTx samples presented in Figure (2c). It displays two strong peaks, meant as the disorder peak (D, situated at $1357 \mathrm{~cm}^{-1}$ ) and the graphitic peak $\left(\mathrm{G}\right.$, at $\left.\sim 1592 \mathrm{~cm}^{-1}\right)$ which are attributed to reduced graphene oxide. For $\mathrm{TiO}_{2}$, a sharp Raman scattering peak for free status anatase nanoparticles is usually seen at $143 \mathrm{~cm}^{-1}$. Conversely, the $\mathrm{TiO}_{2}$ anatase peak was seen at $157 \mathrm{~cm}^{-1}$. The blue shift from $143 \mathrm{~cm}^{-1}$ to $157 \mathrm{~cm}^{-1}$ might be ascribed to the interaction of 
RG and $\mathrm{TiO}_{2}$. The peaks at $\sim 215,410,520$ and $630 \mathrm{~cm}^{-1}$ are related to the different vibration modes of anatase [39].

The morphologies of the magnetite with various amounts of reduced graphene oxide $(10 \%, 20 \%$ and $30 \%)$ are seen by HRTEM in Figure (3- a, b and c respectively). As indicated, the gray part demonstrates the $\mathrm{RG}$, while the dark part demonstrates the aggregates of $\mathrm{Fe}_{3} \mathrm{O}_{4}$ nanoparticles. The magnetite can be distinguished clearly in MRG (10 \% and 20\% respectively). Conversely at MRG30, Graphene tends to cover whole the nanoparticles and hinder activity of these particles [40].

The TEM of the MRGT25, 50 and 75 composites were observed in Figure (3- d, e and $\mathrm{f}$ respectively). The loading amount of $\mathrm{TiO}_{2}$ on $\mathrm{RG}$ sheets is compatible with the EDX results [41].

The EDX spectrum shows the existence of $\mathrm{Fe}, \mathrm{O}$ and $\mathrm{C}$ peaks in MRG composite. The EDX analysis reveals that the ratio of Fe decreases with increasing of graphene content. This observation is in good agreement with the ratio used to prepare the composites as illustrated in Table 1. The EDX results for the MRGTx composites show the existence of $\mathrm{Ti}, \mathrm{Fe}, \mathrm{O}$ and $\mathrm{C}$ elements. The increase of the atomic percentages of Ti can be clearly seen from Table 1: MRGT75 > MRGT50 > MRGT25.

Table 1. EDX data showing the composition of all prepared samples. 


\begin{tabular}{c|c|c|c|c}
\hline & \multicolumn{5}{|c}{ Atomic \% } \\
\cline { 2 - 5 } & $\mathrm{O}$ & $\mathrm{C}$ & $\mathrm{Fe}$ & Ti \\
\hline MRG10 & 21 & 47 & 32 & - \\
MRG20 & 16 & 59 & 25 & - \\
MRG30 & 5 & 91 & 4 & - \\
MRGT50 & 12 & 73 & 12 & 3 \\
MRGT75 & 12 & 72 & 9 & 7 \\
\hline
\end{tabular}

The successful incorporation of $\mathrm{rGO}$ sheets in the $\mathrm{Fe}_{3} \mathrm{O}_{4}$ nanoparticles was revealed by the typical FTIR spectrum shown in Figure (4a). The broad band located at about $3400 \mathrm{~cm}^{-1}$ was assigned to the stretching vibration of $\mathrm{O}-\mathrm{H}$.

The absorption band at $600 \mathrm{~cm}^{-1}$ can be considered as a combination of $\mathrm{Fe}-\mathrm{O}$ vibrations, demonstrating the effective blending of $\mathrm{Fe}_{3} \mathrm{O}_{4}$ nanoparticles and rGO sheets [42]. The absorption band showing up at $1570 \mathrm{~cm}^{-1}$ is related to the skeletal vibration of rGO sheets, which proves the formation of rGO [43].

In Figure (4b) The band at $1400 \mathrm{~cm}^{-1}$ appear due to the Ti-O-C vibration, which confirms the successful interaction between $\mathrm{TiO}_{2}$ and $\mathrm{C}$. In addition, good dispersion of $\mathrm{TiO}_{2}$ on reduced graphene oxide (RG) was confirmed with the 
presence of the absorption band at $584 \mathrm{~cm}^{-1}$ attributed to the presence of $\mathrm{Ti}-\mathrm{O}-\mathrm{Ti}$ bond on the surface of MRGT nanocomposite [44].

VSM technique was performed to measure the magnetic behavior of both $\mathrm{Fe}_{3} \mathrm{O}_{4}$ nanoparticles and MRG nanocomposite. VSM is a suitable technique to find the magnetic behavior of any sample. VSM was performed at room temperature and the magnetic behavior results of MRG 10, 20 and 30 are shown in the Figure (5a). The $\mathrm{Fe}_{3} \mathrm{O}_{4}$ nanoparticles and $\mathrm{MRG}$ nanocomposites demonstrate magnetization hysteresis loops. These magnetization hysteresis loops are S-like curves. All samples of MRG10, 20 and 30 demonstrated that they have a super paramagnetic behavior with a saturation magnetization of 50, 47.3 and $40.6 \mathrm{emu} / \mathrm{g}$, respectively. These values are suitable to easily separate the photocatalysts from the mixture by external magnet and to use it again in other processes. $\mathrm{Fe}_{3} \mathrm{O}_{4}$ nanopowder displays ferromagnetic behavior with a saturation magnetization of $51 \mathrm{emu} / \mathrm{g}$, which was observed to be higher than that of MRG nanocomposites. The smaller value of saturation magnetization in MRG nanocomposites could be attributed to the existence of RG nanosheet in the nanocomposites. [45],[46].

According to the magnetization curves in Figure (5b), the saturation magnetization of the MRGT (25, 50 and 75 proportion) decreases to 34.7, 22.4 and $9.4 \mathrm{emu} / \mathrm{g}$ respectively from $51 \mathrm{emu} / \mathrm{g}$ in the primary $\mathrm{Fe}_{3} \mathrm{O}_{4}$ sample because of the presence of nonmagnetic materials in the surface of MRG nanocomposite. However, this value 
is still adequate for the magnetic separation of the catalyst with a suitable magnet field. The reversibility in hysteresis loop confirms that there is no aggregation occurs to the nanoparticles in the magnetic fields [47].

Figure (6a) presents UV-vis diffuse reflectance spectra of MRG10, 20 and 30 samples. The spectra of sample MRG20 have a red shift for about $25 \mathrm{~nm}$ in comparison to MRG10. This indicates the decrease of the band gap energy. The values of band gap energy $\mathrm{Eg}$ is $1.8,1.4$ and $1.64 \mathrm{eV}$ for MRG10, 20 and 30 respectively. The Eg values were calculated from the $(F(R) h v)^{1 / 2}$ versus hv plots, where $F(R)=(1-R) / 2 R$ [48]. The little blue shift of MRG30 is due to block part of visible light by some layers of reduced graphene to reach to magnetite nanoparticles. The best ratio is for MRG20 which gives the smallest Eg (1.4 ev). UV-vis diffuse reflectance of MRGT25, 50 and 75 is shown in Figure (6b). The MRGT25, 50 and 75 show a blue shift where Eg was 2.3, 2.42 and $2.8 \mathrm{eV}$ respectively. MRGT50 is an active in the visible region.

The photoactivity has been measured and evaluated in the following part. Thus, the incorporation of $\mathrm{Fe}_{3} \mathrm{O}_{4}-\mathrm{rGO}$ into $\mathrm{TiO}_{2}$ has been created energetic levels which has been decreased the band gap energy of $\mathrm{TiO}_{2}$ to shift the absorption edge of $\mathrm{TiO}_{2}$ into the visible range.

\section{Catalytic activity of MRGx and MRGTx samples}


In order to determine the optimal photocatalyst of MRG (either MRG10, 20 or 30) to be used as a support to load $\mathrm{TiO}_{2}$ nanoparticle on its surface, the photocatalytic degradation of $\mathrm{TZ}$ dye in visible light was performed at room temperature by varying the time from 0 to $210 \mathrm{~min}$. The effect of time on the rate of degradation indicates that optimum catalyst loading was MRG20 as shown in Figure (7). The rate of degradation increases with increasing the amount of loading of graphene on the surface of magnetite from MRG10 to MRG20. In MRG30, the rate of degradation has been decreased. This is probably due to the enrichment of loading graphene (rGO) on magnetite surface that leads to the complete cover of nanoparticles and hinder the photocatalytic activity of these particles. This observation has been matched with the band gap data and TEM images.

To study the TZ degradation by MRGT25, 50 and 75, an experiment was performed at room temperature by varying the time from 0 to $210 \mathrm{~min}$. The effect of time on the rate of degradation indicates that the optimum catalyst loading on MRG20 is MRGT50 as shown in Figure (8). The degradation rate has been increased with the increase of the $\mathrm{TiO}_{2}$ amount from MRGT25 to MRGT50. Otherwise, the degradation rate of MRGT75 has been decreased. This is probably due to the excess of titanium dioxide has been shifted the composite to work in UV region. It has less activity in visible light. For $\mathrm{TiO}_{2}$, the degradation efficiency of 
TZ dye was just $10 \%$ because $\mathrm{TiO}_{2}$ has a wide band gap and it is not active in visible light range.

\section{The most effective concentration of MRGT50 and endure against high concentration.}

To determine the optimal amount of the MRGT50 sample, photocatalytic degradation has been performed at room temperature by varying the amount of catalyst from 0.15 to $0.3 \mathrm{~g} / \mathrm{l}$. The effect of MRGT50 loadings on the rate of degradation indicates that optimum catalyst concentration is $0.2 \mathrm{~g} / 1$ as shown in Figure (9). The rate increases with the increase in catalyst concentration from 0.15 to $0.2 \mathrm{~g} / \mathrm{l}$. This is probably due to the increase in the amount of photocatalyst, which increases the number of photons and dye molecules absorbed. The increase of the catalyst concentration to more than $0.2 \mathrm{~g} / \mathrm{l}$ results in the decrease of degradation rate. This phenomenon may be explained by the aggregation of MRGT50 at high concentrations. It causes a decrease in the number of surface active sites, which increases the opacity and lights scattering of MRGT50, leading to a decrease in the passage of irradiation through the sample.

Photocatalytic degradations are performed as well at different concentrations of $\mathrm{TZ}$ 50, 100, 150 and $200 \mathrm{ppm}$, against MRGT50 [0.2g/l], at room temperature. Degradation rate appears to decrease with increasing $\mathrm{TZ}$ concentration in Figure 
(10). This could be attributed to the fact that active sites of the photocatalyst are occupied by TZ molecules and fewer photons can reach the surface of the catalyst. Therefore, the possibility of photocatalyst excitation is diminished. At higher concentration levels, the screening effect also dominates and hence, degradation efficiency decreases.

The prepared materials (MRGT50) have been achieved high degradation of tartrazine (azo-dye) (Table 2). Besides, MRGT50 has magnetic properties in order to facilitate its extraction from solution.

Photocatalytic stability of MRGT50 was evaluated by reusability test. The test was carried out for four times under visible light as shown in Figure (11). The weight of MRGT50 (extracted from $60 \mathrm{~mL}$ of solution) after each run was stable (12 mg). The degradation rate of tartrazine reached $90 \%$ for four cycles. This indicates that $\mathrm{Fe}_{3} \mathrm{O}_{4} / \mathrm{rGO} / \mathrm{TiO}_{2}$ is a promising photocatalyst.

Table 2. Maximum degradation of various photocatalysts for TZ dye.

\begin{tabular}{cccccc}
\hline Photocatalysts & $\begin{array}{c}\text { Started } \\
\text { concentration(ppm) }\end{array}$ & Radiation & Time(min.) & Degradation & Ref. \\
& source & & $(\%)$ & \\
\hline Ag-silicon & 5.5 & UV & 200 & $<10 \%$ & {$[14]$} \\
nanowires & & & & & \\
(SiNWs) & 5.5 & UV & 200 & $<10 \%$ & {$[14]$} \\
Au-(SiNWs) & 5.5 & UV & 200 & $11 \%$ & {$[14]$} \\
Pt-(SiNWs) & & & &
\end{tabular}




\begin{tabular}{cccccc}
$\mathrm{H}-\mathrm{SiNWs}$ & 5.5 & $\mathrm{UV}$ & 200 & $27.39 \%$ & {$[14]$} \\
$\mathrm{Pd}-(\mathrm{SiNWs})$ & 5.5 & $\mathrm{UV}$ & 200 & $47.45 \%$ & {$[14]$} \\
$\mathrm{Cu}$-(SiNWs) & 5.5 & $\mathrm{UV}$ & 200 & $67.45 \%$ & {$[14]$} \\
$\mathrm{Cu}-(\mathrm{SiNWs})$ with & 5.5 & $\mathrm{UV}$ & 200 & $95.48 \%$ & {$[14]$} \\
$\mathrm{H}_{2} \mathrm{O}_{2}$ & & & & \\
$\mathrm{~N}$-doped $\mathrm{TiO}_{2}$ & - & Visible & 90 & $50 \%$ & {$[49]$} \\
$\mathrm{N}$-doped $\mathrm{TiO}_{2}$ with & - & Visible & 90 & $85 \%$ & {$[49]$} \\
organic phosphors & & & & & [50] \\
$\mathrm{ZnO}$ & 40 & UV & 60 & $92.9 \%$ & This work \\
MRG20 & 50 & Visible & 210 & $33 \%$ & This work \\
MRGT50 & 50 & Visible & 210 & $95.5 \%$ & \\
\hline
\end{tabular}

The degradation mechanism, based on all the results reported here and the energy band structure of $\mathrm{Fe}_{3} \mathrm{O}_{4} / \mathrm{rGO} / \mathrm{TiO}_{2}$ heterointerfaces are shown in Figure (12). Under light irradiation, electrons and holes are generated in the composite. The photogenerated electrons in the $\mathrm{CB}$ of magnetite can be transferred to the $\mathrm{CB}$ of $\mathrm{TiO}_{2}$ via $\mathrm{rGO}$, which acted as a conductive layer to enhance the electron hole separation [51-53]. All techniques have been used to characterize the structure of composite which proved that Janus structure of $\mathrm{Fe}_{3} \mathrm{O}_{4}$ and $\mathrm{TiO}_{2}$ in the presence of conductive layer (rGO). The presence of an interlayer (rGO) facilitated the migration of electron into $\mathrm{TiO}_{2}$ and accumulated hole in $\mathrm{Fe}_{3} \mathrm{O}_{4}$. Then $\mathrm{OH}^{\cdot}$ radicals have been produced by holes which have strong oxidizing power. Also, 
photogenerated electron are produced $\mathrm{O}_{2}{ }^{-*}$ which play important role for degradation of tartrazine, by the following mechanism

\begin{tabular}{|c|c|c|}
\hline MRGT50 + hv & $\longrightarrow \quad\left(\mathrm{h}^{+}\right) \mathrm{Fe}_{3} \mathrm{O}_{4} / /$ conductive layer of $\mathrm{rGO} / /\left(\mathrm{e}^{-}\right) \mathrm{TiO}_{2}$ & equation (1) \\
\hline (e) $\mathrm{TiO}_{2}+\mathrm{O}_{2}$ & $\longrightarrow \mathrm{O}_{2}{ }^{\cdot-}$ & equation (2) \\
\hline $\mathrm{H}_{2} \mathrm{O}+\mathrm{O}_{2} \cdot$ & $\longrightarrow{ }_{2} \mathrm{OH}^{\cdot}$ & equation (3) \\
\hline$\left(h^{+}\right) \mathrm{Fe}_{3} \mathrm{O}_{4}+\mathrm{H}_{2} \mathrm{O}$ & $\longrightarrow \mathrm{OH}^{\bullet}+\mathrm{H}^{+}$ & equation (4) \\
\hline $\mathrm{H}_{2} \mathrm{O}+\mathrm{O}_{2}{ }^{\cdot-}+\mathrm{H}^{+}$ & $\longrightarrow \mathrm{OH}^{-}+\mathrm{H}_{2} \mathrm{O}_{2}+\mathrm{OH}^{-}$ & equation (5) \\
\hline $\mathrm{H}_{2} \mathrm{O}_{2}+\mathrm{e}^{-}$ & $\longrightarrow \mathrm{OH}^{\cdot}+\mathrm{OH}^{-}$ & equation (6) \\
\hline $\mathrm{OH}^{-}+\mathrm{h}^{+}$ & $\longrightarrow \mathrm{OH}^{\cdot}$ & equation (7) \\
\hline $\mathrm{OH}^{\bullet}+\mathrm{TZ}$ & $\longrightarrow$ degradation of tartrazine dye & equation (8) \\
\hline
\end{tabular}

\section{Conclusion}

A magnetically separable MRG and MRGT photocatalyst has been successfully prepared. TEM observations indicate that reduced graphene sheets are fully exfoliated and decorated with $\mathrm{Fe}_{3} \mathrm{O}_{4}$ and $\mathrm{TiO}_{2}$ nanoparticles. The photocatalytic activity measurements show that coupling $\mathrm{Fe}_{3} \mathrm{O}_{4}$ and $\mathrm{TiO}_{2}$ nanoparticles with reduced graphene oxide sheets leads to high photocatalytic activity in degradation of TZ under visible light irradiation. The degradation efficiency reaches more than 95\%. In contrast, $\mathrm{TiO}_{2}$ alone is almost inactive under visible light. The designed nanocomposites were collected and separated easily from solution just by applying an external magnetic field after degradation of organic pollutant. The weight of 
MRGT50 after each photocatalysis run was stable (12 mg). This prepared material is promising to use also in dye-sensitized solar cell because it is highly activity in visible region combined with good efficiency.

\section{Acknowledgment}

Amr Nada acknowledges support from the Science and Technology Development Fund and the Embassy of France in Egypt

\section{References}

[1] R. Saravanan, S. Karthikeyan, V. Gupta, G. Sekaran, V. Narayanan, and A. Stephen, "Enhanced photocatalytic activity of $\mathrm{ZnO} / \mathrm{CuO}$ nanocomposite for the degradation of textile dye on visible light illumination," Materials Science and Engineering: C, vol. 33, pp. 91-98, 2013.

[2] T. T. Hameed, B. M. Fahad, and N. S. Ali, "USING LOW COST WASTE GLASS ADSORBENT FOR METHYL VIOLET REMOVAL FROM WASTE WATER," 2017.

[3] S. Papić, N. Koprivanac, A. L. Božić, and A. Meteš, "Removal of some reactive dyes from synthetic wastewater by combined Al (III) coagulation/carbon adsorption process," Dyes and Pigments, vol. 62, pp. 291-298, 2004.

[4] A. Mittal, L. Kurup, and J. Mittal, "Freundlich and Langmuir adsorption isotherms and kinetics for the removal of Tartrazine from aqueous solutions using hen feathers," Journal of hazardous materials, vol. 146, pp. 243-248, 2007.

[5] I. G. Bacioiu, L. Stoica, C. Constantin, and A. M. Stanescu, "Adsorption Equilibrium and Kinetics Modeling for Tartrazine (E102)-Fe (II) Based Adsorbent System," REVISTA DE CHIMIE, vol. 67, pp. 2391-2395, 2016.

[6] A. Weisz, C. D. Ridge, J. A. Roque, E. P. Mazzola, and Y. Ito, "Preparative separation of two subsidiary colors of FD\&C Yellow No. 5 (Tartrazine) using spiral high-speed counter-current chromatography," Journal of Chromatography A, vol. 1343, pp. 91-100, 2014.

[7] Z. Atlı Şekeroğlu, B. Güneş, S. Kontaş Yedier, V. Şekeroğlu, and B. Aydın, "Effects of tartrazine on proliferation and genetic damage in human lymphocytes," Toxicology Mechanisms and Methods, pp. 1-17, 2017.

[8] A. Rafati, N. Nourzei, S. Karbalay-Doust, and A. Noorafshan, "Using vitamin E to prevent the impairment in behavioral test, cell loss and dendrite changes in medial prefrontal cortex induced by tartrazine in rats," Acta histochemica, vol. 119, pp. 172-180, 2017. 
[9] M. A. Habila, Z. A. ALOthman, R. Ali, A. A. Ghafar, and M. S. E. D. Hassouna, "Removal of Tartrazine Dye onto Mixed-Waste Activated Carbon: Kinetic and Thermodynamic Studies," CLEAN-Soil, Air, Water, vol. 42, pp. 1824-1831, 2014.

[10] G. El-Desoky, A. Abdel-Ghaffar, Z. Al-Othman, M. Habila, Y. Al-Sheikh, H. Ghneim, et al., "Curcumin protects against tartrazine-mediated oxidative stress and hepatotoxicity in male rats," European Review for Medical and Pharmacological Sciences, vol. 21, pp. 635-645, 2017.

[11] N. Arabzadeh, A. Khosravi, A. Mohammadi, and N. M. Mahmoodi, "Enhanced photodegradation of hazardous tartrazine by composite of nanomolecularly imprinted polymer-nanophotocatalyst with high efficiency," Desalination and Water Treatment, vol. 57, pp. 3142-3151, 2016.

[12] L. Rizzo, H. Selcuk, A. Nikolaou, S. Meriç Pagano, and V. Belgiorno, "A comparative evaluation of ozonation and heterogeneous photocatalytic oxidation processes for reuse of secondary treated urban wastewater," Desalination and Water Treatment, vol. 52, pp. 1414-1421, 2014.

[13] C. Sichel, J. Blanco, S. Malato, and P. Fernandez-Ibanez, "Effects of experimental conditions on E. coli survival during solar photocatalytic water disinfection," Journal of Photochemistry and photobiology A: Chemistry, vol. 189, pp. 239-246, 2007.

[14] S. Naama, T. Hadjersi, H. Menari, G. Nezzal, L. B. Ahmed, and S. Lamrani, "Enhancement of the tartrazine photodegradation by modification of silicon nanowires with metal nanoparticles," Materials Research Bulletin, vol. 76, pp. 317-326, 2016.

[15] C. Y. P. Ayekoe, D. Robert, and D. G. Lanciné, "Combination of coagulation-flocculation and heterogeneous photocatalysis for improving the removal of humic substances in real treated water from Agbô River (Ivory-Coast)," Catalysis Today, vol. 281, pp. 2-13, 2017.

[16] Y. Wu, Y. Zhou, Y. Liu, Y. Wang, L. Yang, and C. Li, "Photocatalytic performances and characterizations of sea urchin-like N, Ce codoped TiO2 photocatalyst," Materials Research Innovations, vol. 21, pp. 33-39, 2017.

[17] S. Ghasemi, S. Hashemian, A. Alamolhoda, I. Gocheva, and S. R. Setayesh, "Plasmon enhanced photocatalytic activity of Au@ TiO 2-graphene nanocomposite under visible light for degradation of pollutants," Materials Research Bulletin, vol. 87, pp. 40-47, 2017.

[18] H. H. El-Maghrabi, A. Barhoum, A. A. Nada, Y. M. Moustafa, S. M. Seliman, A. M. Youssef, et al., "Synthesis of mesoporous core-shell CdS@ TiO 2 (OD and 1D) photocatalysts for solar-driven hydrogen fuel production," Journal of Photochemistry and Photobiology A: Chemistry, vol. 351, pp. 261-270, 2018.

[19] M. Nasr, S. Balme, C. Eid, R. Habchi, P. Miele, and M. Bechelany, "Enhanced Visible-Light Photocatalytic Performance of Electrospun rGO/TiO2 Composite Nanofibers," The Journal of Physical Chemistry C, 2016.

[20] B. Bhanvase, T. Shende, and S. Sonawane, "A review on graphene-TiO2 and doped graphene$\mathrm{TiO} 2$ nanocomposite photocatalyst for water and wastewater treatment," Environmental Technology Reviews, vol. 6, pp. 1-14, 2017.

[21] M. L. Yola, N. Atar, T. Eren, H. Karimi-Maleh, and S. Wang, "Correction: Sensitive and selective determination of aqueous triclosan based on gold nanoparticles on polyoxometalate/reduced graphene oxide nanohybrid," RSC Advances, vol. 5, pp. 72590-72591, 2015.

[22] N. Atar, T. Eren, M. L. Yola, H. Gerengi, and S. Wang, "Fe@ Ag nanoparticles decorated reduced graphene oxide as ultrahigh capacity anode material for lithium-ion battery," lonics, vol. 21, pp. 3185-3192, 2015.

[23] N. Atar, T. Eren, and M. L. Yola, "Ultrahigh capacity anode material for lithium ion battery based on rod gold nanoparticles decorated reduced graphene oxide," Thin Solid Films, vol. 590, pp. 156-162, 2015.

[24] S. Elçin, M. L. Yola, T. Eren, B. Girgin, and N. Atar, "Highly Selective and Sensitive Voltammetric Sensor Based on Ruthenium Nanoparticle Anchored Calix [4] amidocrown-5 Functionalized 
Reduced Graphene Oxide: Simultaneous Determination of Quercetin, Morin and Rutin in Grape Wine," Electroanalysis, vol. 28, pp. 611-619, 2016.

[25] G. Kotan, F. Kardaş, Ö. A. Yokuş, O. Akyıldırım, H. Saral, T. Eren, et al., "A novel determination of curcumin via Ru@ Au nanoparticle decorated nitrogen and sulfur-functionalized reduced graphene oxide nanomaterials," Analytical Methods, vol. 8, pp. 401-408, 2016.

[26] Ö. A. Yokuş, F. Kardaş, O. Akyıldırım, T. Eren, N. Atar, and M. L. Yola, "Sensitive voltammetric sensor based on polyoxometalate/reduced graphene oxide nanomaterial: application to the simultaneous determination of I-tyrosine and I-tryptophan," Sensors and Actuators B: Chemical, vol. 233, pp. 47-54, 2016.

[27] O. Akyıldırım, H. Yüksek, H. Saral, I. Ermiş, T. Eren, and M. L. Yola, "Platinum nanoparticles supported on nitrogen and sulfur-doped reduced graphene oxide nanomaterial as highly active electrocatalysts for methanol oxidation," Journal of Materials Science: Materials in Electronics, vol. 27, pp. 8559-8566, 2016.

[28] X. Xie, J. Long, J. Xu, L. Chen, Y. Wang, Z. Zhang, et al., "Nitrogen-doped graphene stabilized gold nanoparticles for aerobic selective oxidation of benzylic alcohols," RSC Advances, vol. 2, pp. 12438-12446, 2012.

[29] J.-J. Zhang, X. Liu, T. Ye, G.-P. Zheng, X.-C. Zheng, P. Liu, et al., "Novel assembly of homogeneous reduced graphene oxide-doped mesoporous TiO 2 hybrids for elimination of Rhodamine-B dye under visible light irradiation," Journal of Alloys and Compounds, vol. 698, pp. 819-827, 2017.

[30] S. Xuan, W. Jiang, X. Gong, Y. Hu, and Z. Chen, "Magnetically separable Fe304/TiO2 hollow spheres: fabrication and photocatalytic activity," The Journal of Physical Chemistry C, vol. 113, pp. 553-558, 2008.

[31] J. Guerrero-Contreras and F. Caballero-Briones, "Graphene oxide powders with different oxidation degree, prepared by synthesis variations of the Hummers method," Materials Chemistry and Physics, vol. 153, pp. 209-220, 2015.

[32] P. Wang, X. Zhou, Y. Zhang, L. Wang, K. Zhi, and Y. Jiang, "Synthesis and application of magnetic reduced graphene oxide composites for the removal of bisphenol $A$ in aqueous solution-a mechanistic study," RSC Advances, vol. 6, pp. 102348-102358, 2016.

[33] M. Deyab, A. A. Nada, and A. Hamdy, "Comparative study on the corrosion and mechanical properties of nano-composite coatings incorporated with TiO 2 nano-particles, TiO 2 nanotubes, and ZnO nano-flowers," Progress in Organic Coatings, vol. 105, pp. 245-251, 2017.

[34] X. Yang, C. Chen, J. Li, G. Zhao, X. Ren, and X. Wang, "Graphene oxide-iron oxide and reduced graphene oxide-iron oxide hybrid materials for the removal of organic and inorganic pollutants," RSC Advances, vol. 2, pp. 8821-8826, 2012.

[35] L. Liu, C. Luo, J. Xiong, Z. Yang, Y. Zhang, Y. Cai, et al., "Reduced graphene oxide (rGO) decorated TiO 2 microspheres for visible-light photocatalytic reduction of $\mathrm{Cr}(\mathrm{VI})$," Journal of Alloys and Compounds, vol. 690, pp. 771-776, 2017.

[36] L. Shahriary and A. A. Athawale, "Graphene oxide synthesized by using modified hummers approach," Int J Renew Energy Environ Eng, vol. 2, pp. 58-63, 2014.

[37] J. Cheng, Q. Shou, J. Wu, F. Liu, V. P. Dravid, and X. Zhang, "Influence of component content on the capacitance of magnetite/reduced graphene oxide composite," Journal of Electroanalytical Chemistry, vol. 698, pp. 1-8, 2013.

[38] H. H. El-Maghrabi, S. M. Abdelmaged, A. A. Nada, F. Zahran, S. A. El-Wahab, D. Yahea, et al., "Magnetic graphene based nanocomposite for uranium scavenging," Journal of Hazardous Materials, vol. 322, pp. 370-379, 2017.

[39] J. Qiu, P. Zhang, M. Ling, S. Li, P. Liu, H. Zhao, et al., "Photocatalytic synthesis of TiO2 and reduced graphene oxide nanocomposite for lithium ion battery," ACS applied materials \& interfaces, vol. 4, pp. 3636-3642, 2012. 
[40] H. H. El-Maghrabi, E. A. Nada, F. S. Soliman, Y. M. Moustafa, and A. E.-S. Amin, "One pot environmental friendly nanocomposite synthesis of novel TiO 2-nanotubes on graphene sheets as effective photocatalyst," Egyptian Journal of Petroleum, 2016.

[41] M. Shi, J. Shen, H. Ma, Z. Li, X. Lu, N. Li, et al., "Preparation of graphene-TiO 2 composite by hydrothermal method from peroxotitanium acid and its photocatalytic properties," Colloids and Surfaces A: Physicochemical and Engineering Aspects, vol. 405, pp. 30-37, 2012.

[42] Y. Gao, D. Zhong, D. Zhang, X. Pu, X. Shao, C. Su, et al., "Thermal regeneration of recyclable reduced graphene oxide/Fe3O4 composites with improved adsorption properties," Journal of Chemical Technology and Biotechnology, vol. 89, pp. 1859-1865, 2014.

[43] M. S. A. Sher Shah, A. R. Park, K. Zhang, J. H. Park, and P. J. Yoo, "Green synthesis of biphasic TiO2-reduced graphene oxide nanocomposites with highly enhanced photocatalytic activity," ACS applied materials \& interfaces, vol. 4, pp. 3893-3901, 2012.

[44] P. Benjwal, M. Kumar, P. Chamoli, and K. K. Kar, "Enhanced photocatalytic degradation of methylene blue and adsorption of arsenic (iii) by reduced graphene oxide ( $\mathrm{rGO}$ )-metal oxide ( $\mathrm{TiO}$ 2/Fe $3 \mathrm{O}$ 4) based nanocomposites," Rsc Advances, vol. 5, pp. 73249-73260, 2015.

[45] P. K. Boruah, D. J. Borah, J. Handique, P. Sharma, P. Sengupta, and M. R. Das, "Facile synthesis and characterization of $\mathrm{Fe} 3 \mathrm{O} 4$ nanopowder and $\mathrm{Fe} 3 \mathrm{O}$ 4/reduced graphene oxide nanocomposite for methyl blue adsorption: A comparative study," Journal of Environmental Chemical Engineering, vol. 3, pp. 1974-1985, 2015.

[46] F. Deng, X. Lu, X. Pei, X. Luo, S. Luo, and D. D. Dionysiou, "Fabrication of ternary reduced graphene oxide/SnS 2/ZnFe 204 composite for high visible-light photocatalytic activity and stability," Journal of Hazardous Materials, 2017.

[47] E. Tabrizian and A. Amoozadeh, "A unique approach to magnetization of metal oxides: nano-Fe 3 O 4@TDI@TiO 2 as a highly efficient, magnetically separable and recyclable heterogeneous nanocatalyst," Catalysis Science \& Technology, vol. 6, pp. 6267-6276, 2016.

[48] J. D. Lindberg and D. G. Snyder, "Determination of the optical absorption coefficient of powdered materials whose particle size distribution and refractive indices are unknown," Applied optics, vol. 12, pp. 573-578, 1973.

[49] V. Vaiano, O. Sacco, G. lervolino, D. Sannino, P. Ciambelli, R. Liguori, et al., "Enhanced visible light photocatalytic activity by up-conversion phosphors modified N-doped TiO 2," Applied Catalysis B: Environmental, vol. 176, pp. 594-600, 2015.

[50] M. Behnajady, N. Modirshahla, and R. Hamzavi, "Kinetic study on photocatalytic degradation of $\mathrm{Cl}$ Acid Yellow 23 by ZnO photocatalyst," Journal of hazardous materials, vol. 133, pp. 226-232, 2006.

[51] Y. Hou, F. Zuo, A. Dagg, and P. Feng, "Visible Light-Driven $\alpha$-Fe2O3 Nanorod/Graphene/BiV1-x Mo x O4 Core/Shell Heterojunction Array for Efficient Photoelectrochemical Water Splitting," Nano letters, vol. 12, pp. 6464-6473, 2012.

[52] W. Wu, C. Jiang, and V. A. Roy, "Recent progress in magnetic iron oxide-semiconductor composite nanomaterials as promising photocatalysts," Nanoscale, vol. 7, pp. 38-58, 2015.

[53] A. A. Nada, M. Nasr, R. Viter, P. Miele, S. Roualdes, and M. Bechelany, "Mesoporous ZnFe2O4@ TiO2 Nanofibers Prepared by Electrospinning Coupled to PECVD as Highly Performing Photocatalytic Materials," The Journal of Physical Chemistry C, vol. 121, pp. 24669-24677, 2017. 

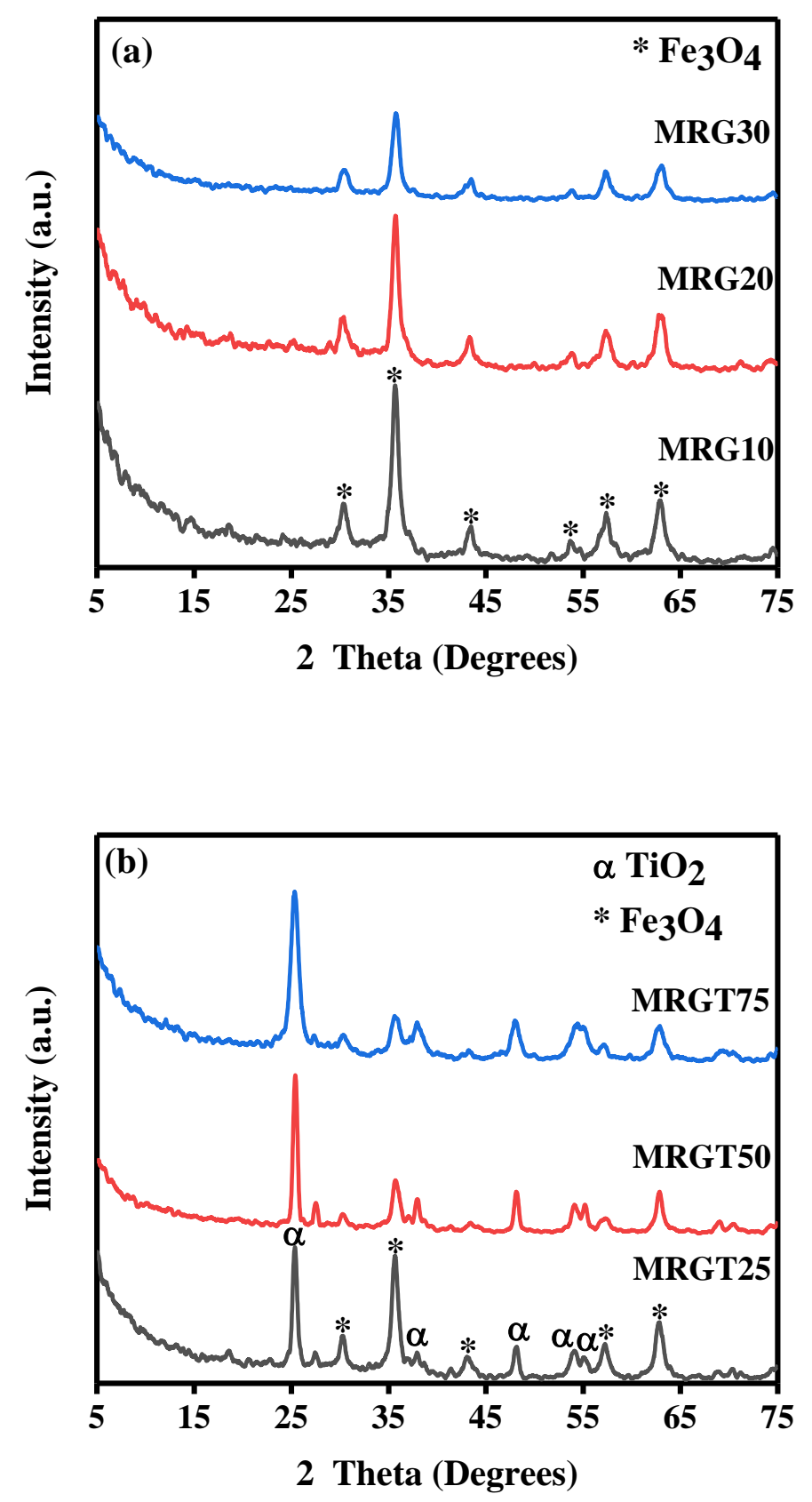

Figure 1. X-ray diffraction patterns of (a) MRG10, 20 and 30 \& (b) MRGT25, 50 and 75 samples. 

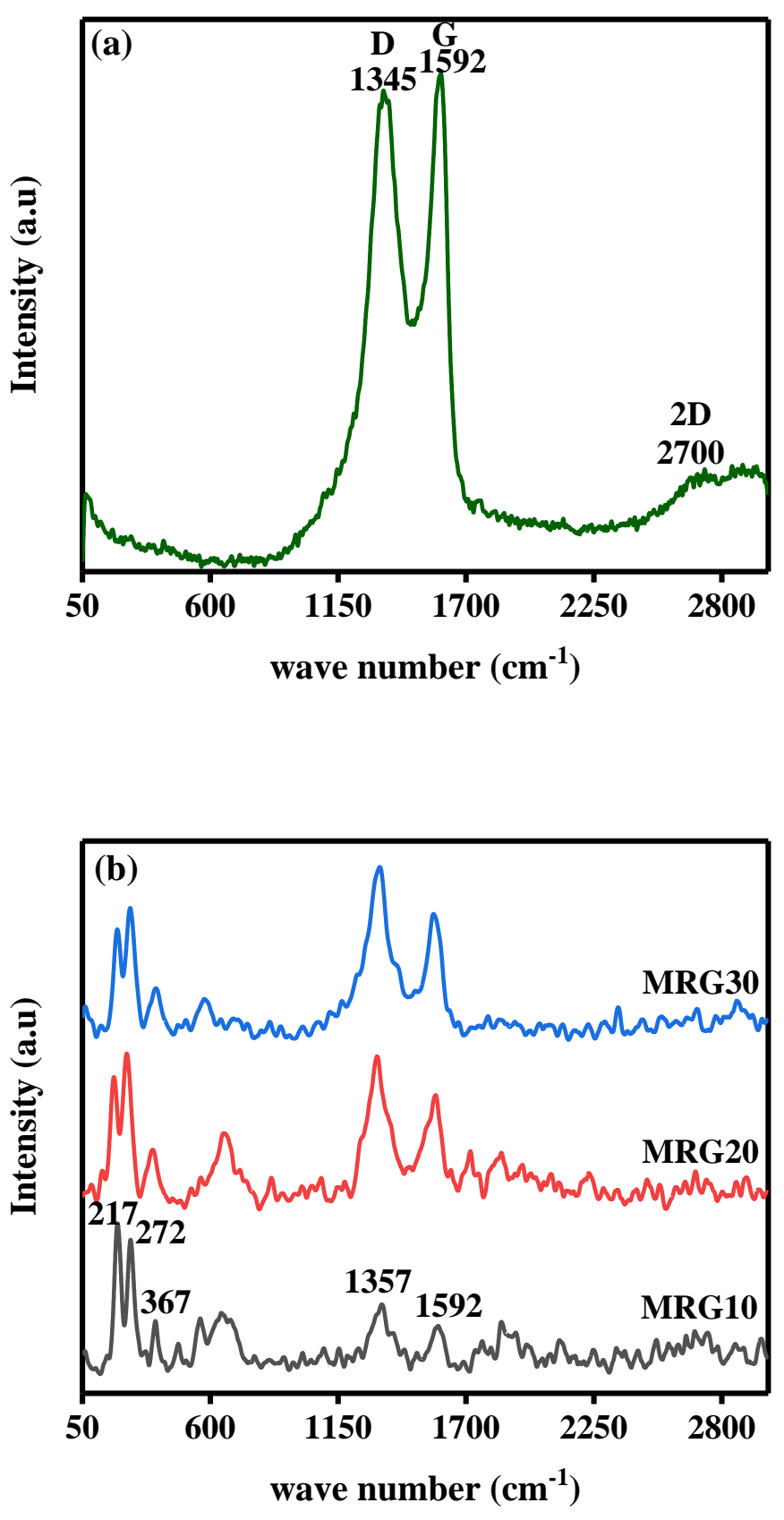


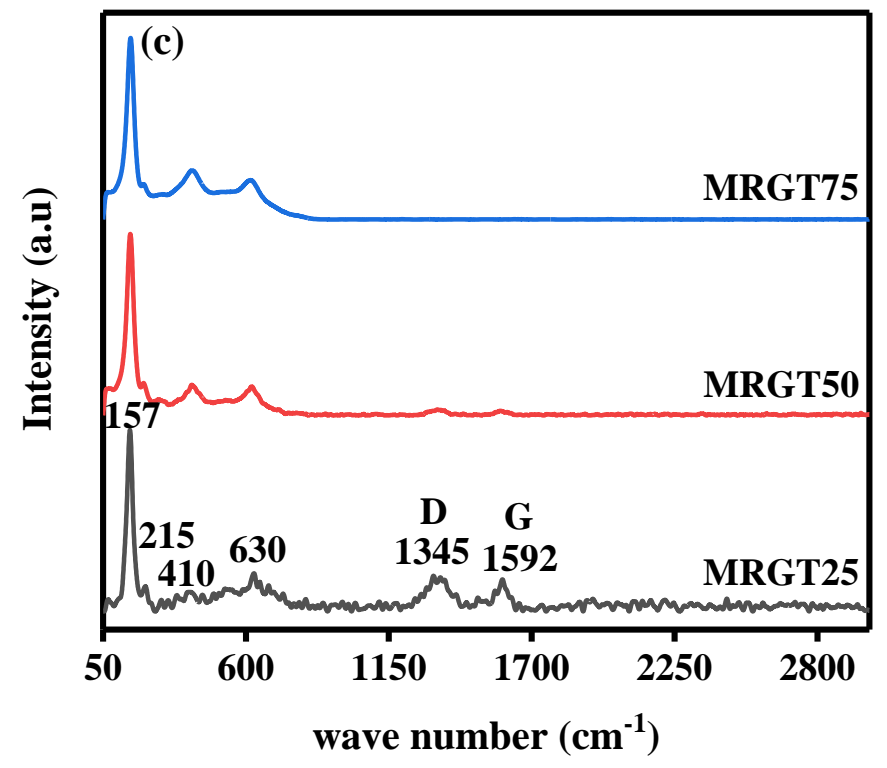

Figure 2. Raman spectra of (a) graphene oxide sample, (b) MRG10, 20 and 30 samples and (c) MRGT25, 50 and 75 samples. 


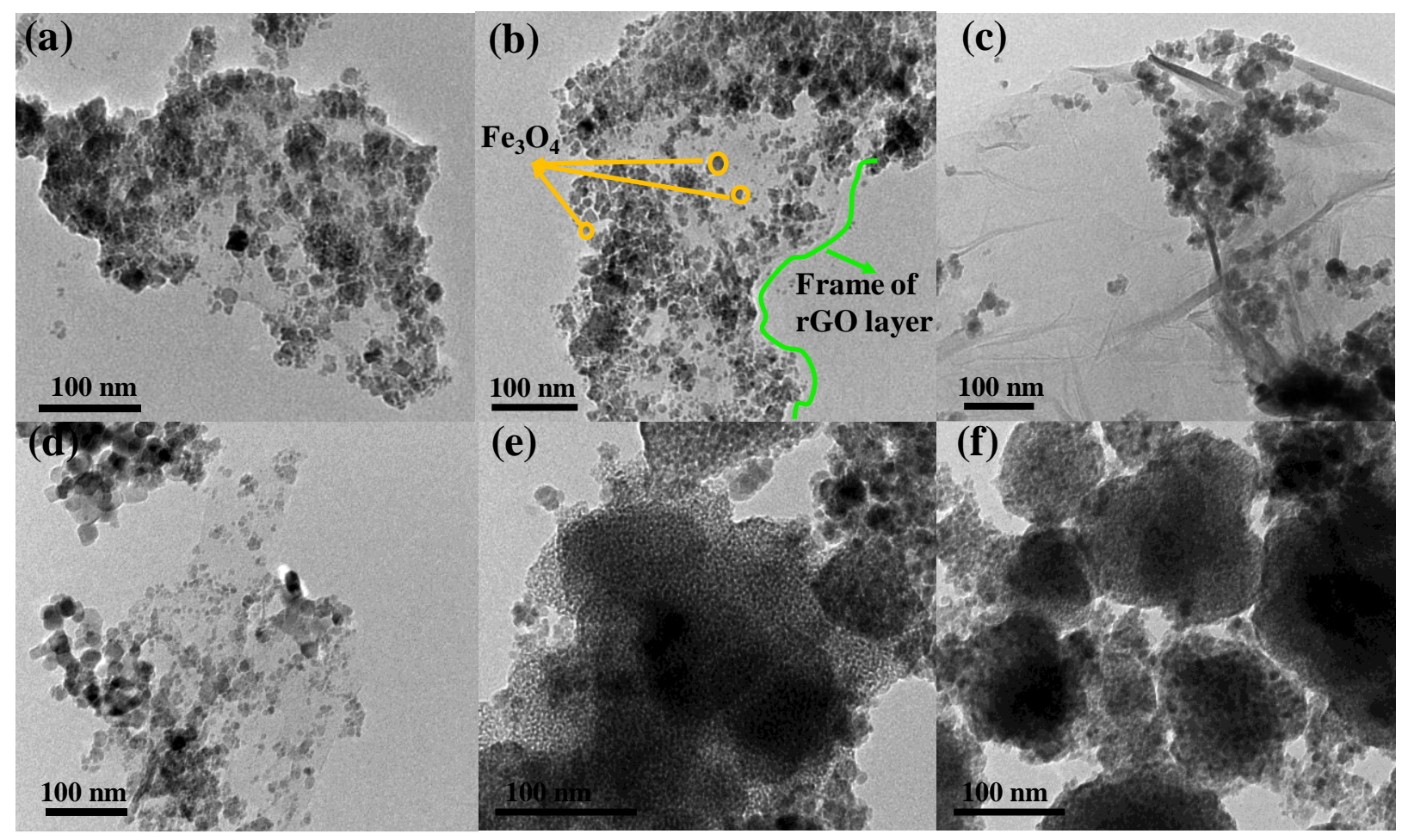

Figure 3. TEM images of (a) MRG10, (b) MRG20, (c) MRG30, (d) MRGT25, (e)

MRGT50 and (f) MRGT75 samples.

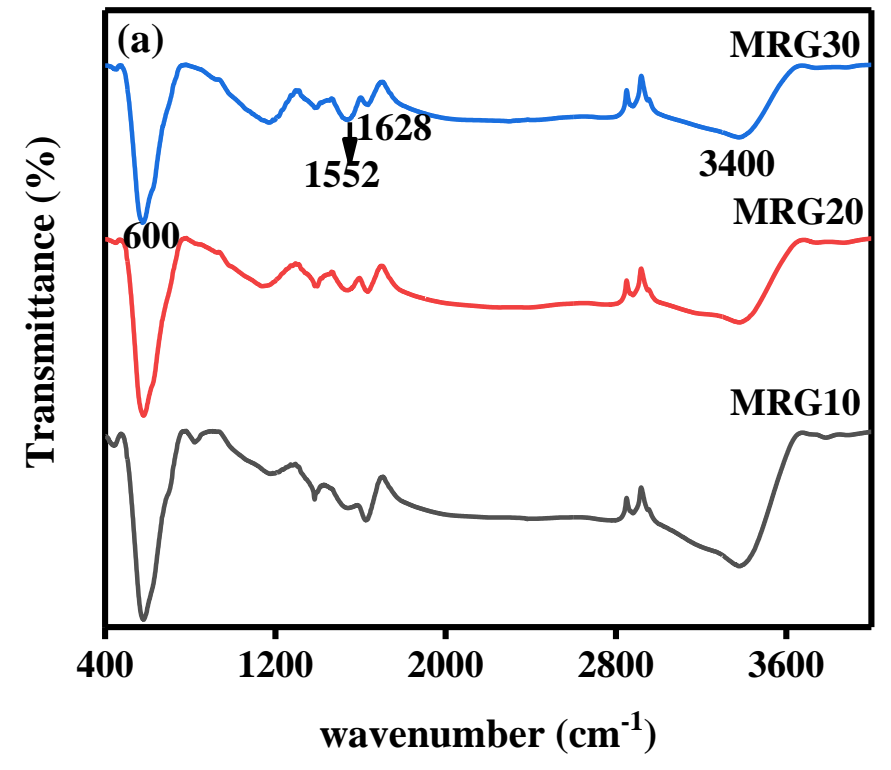




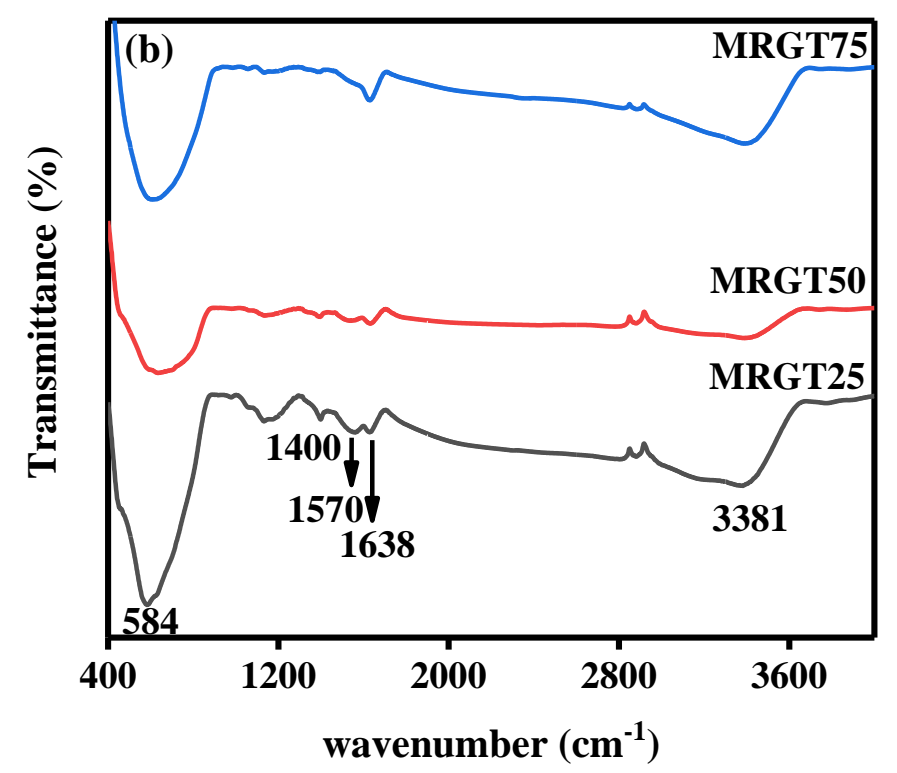

Figure 4. FT-IR spectra of (a) MRG10, 20 and 30 and (b) MRGT25, 50 and 75 samples. 

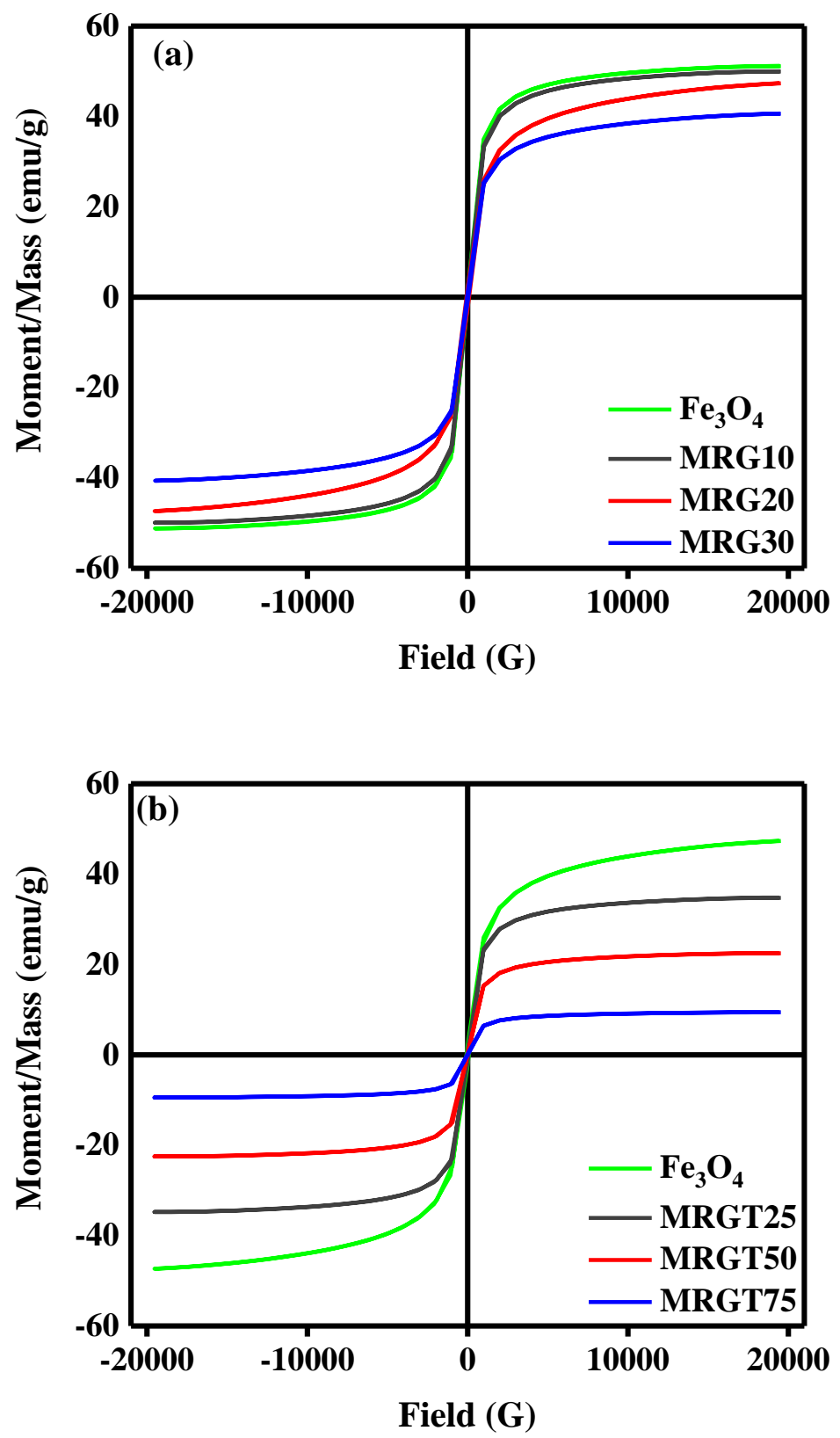

Figure 5. VSM measurements for magnetic nanoparticles, (a) $\mathrm{Fe}_{3} \mathrm{O}_{4}, \mathrm{MRG} 10,20$ and 30 samples and (b) $\mathrm{Fe}_{3} \mathrm{O}_{4}, \mathrm{MRGT25,} 50$ and 75 samples. 

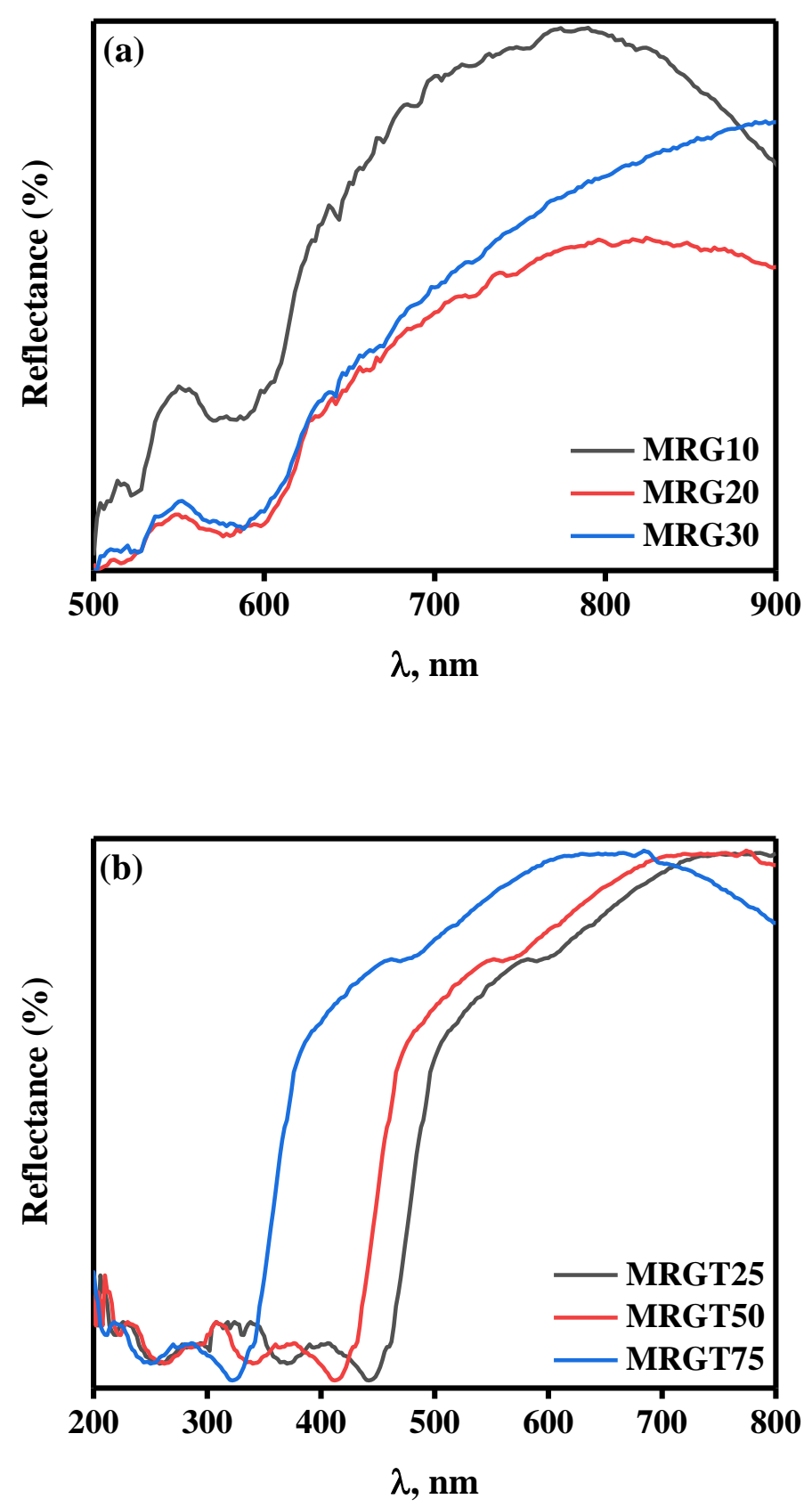

Figure 6. Diffuse reflectance for all prepared samples (a) MRG10, 20 and 30 samples and (b) MRGT25, 50 and 75 samples. 


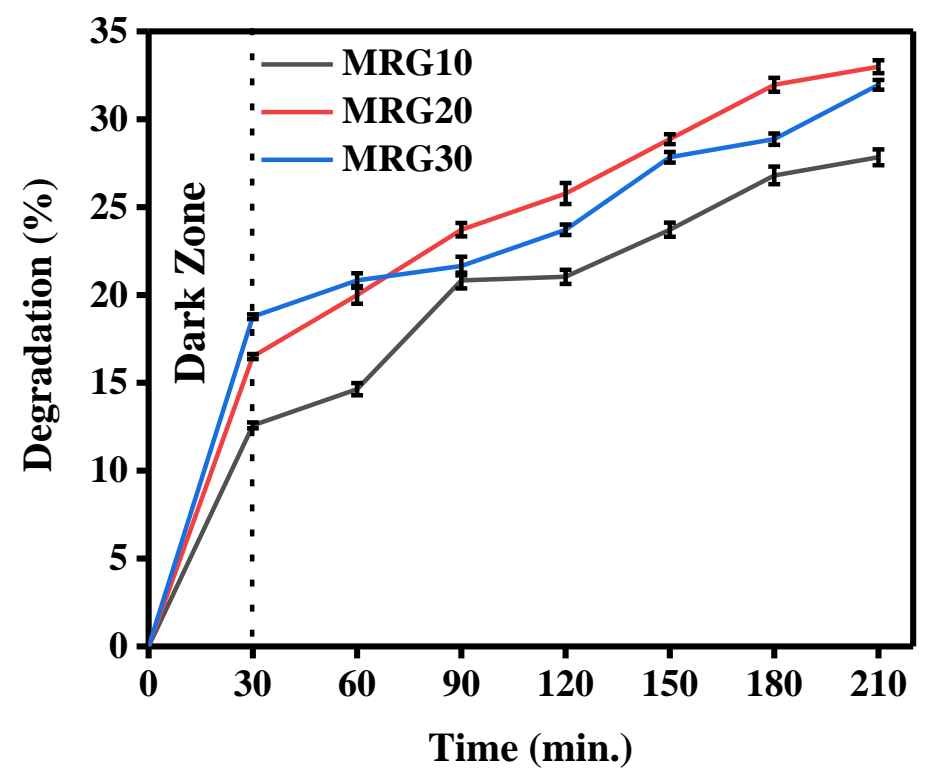

Figure 7. Photocatalytic degradation of tartrazine by 0.2 g MRG10, 20 and 30 samples in $1 \mathrm{~L}(50 \mathrm{ppm}) \mathrm{TZ}$.

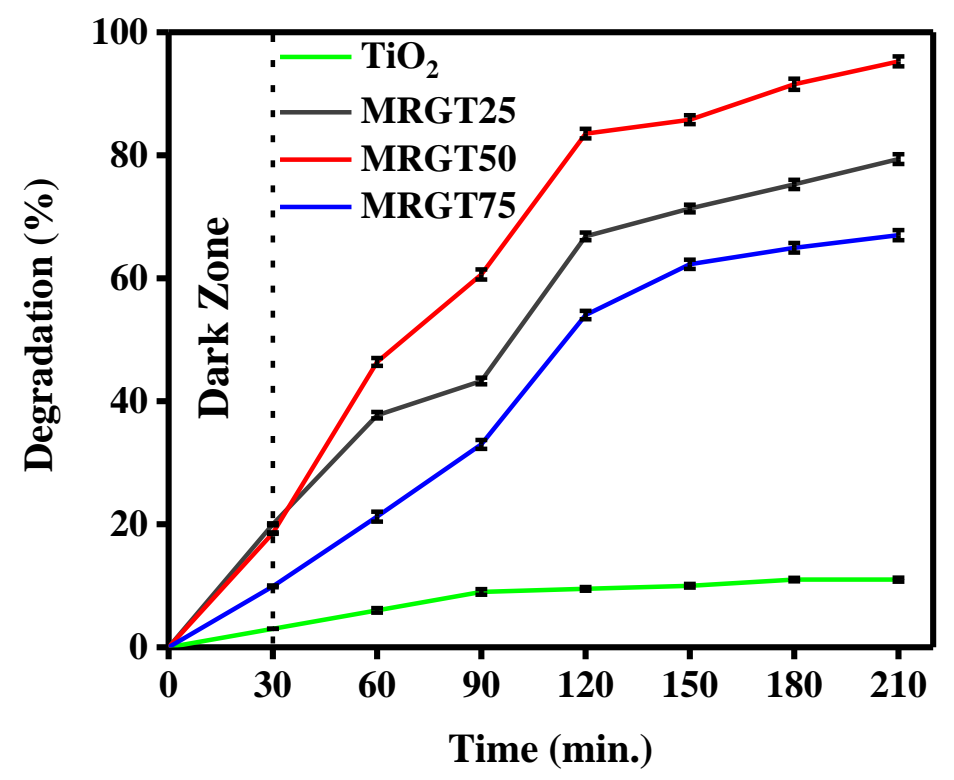

Figure 8. Photocatalytic degradation of $1 \mathrm{~L}-50 \mathrm{ppm}$ TZ by $0.2 \mathrm{~g}$ of MRGT25, 50, 75 and $\mathrm{TiO}_{2}$ samples. 


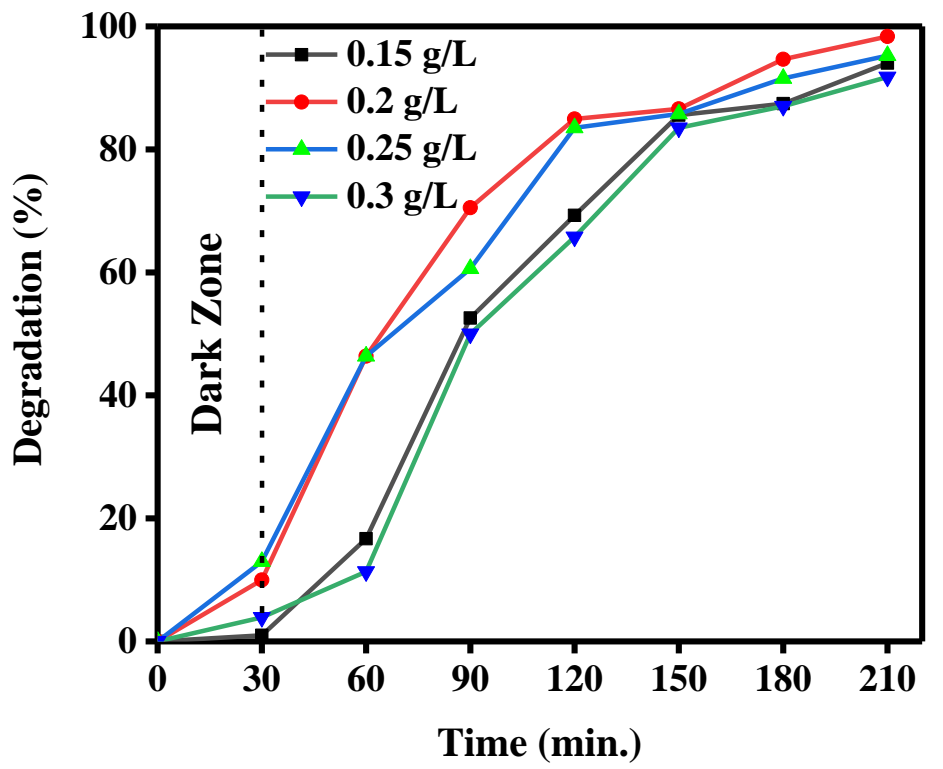

Figure 9. Effect of weight catalyst MRGT50 on degradation of $50 \mathrm{ppm} \mathrm{TZ}$ concentration.

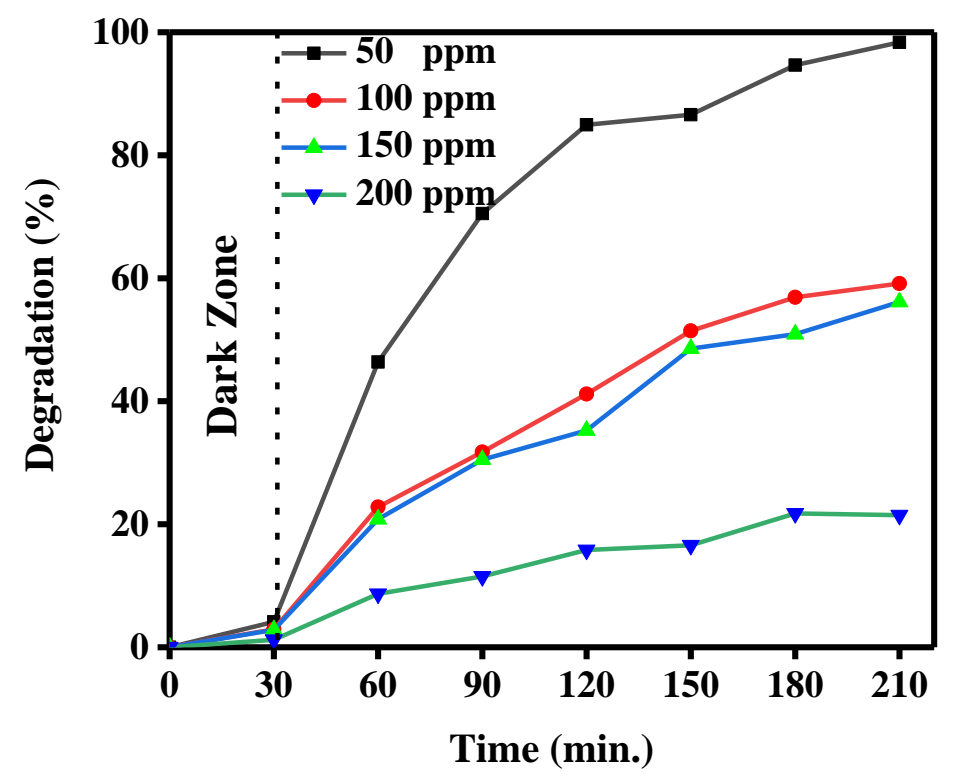

Figure 10. Different concentrations of TZ degradation by MRGT50 


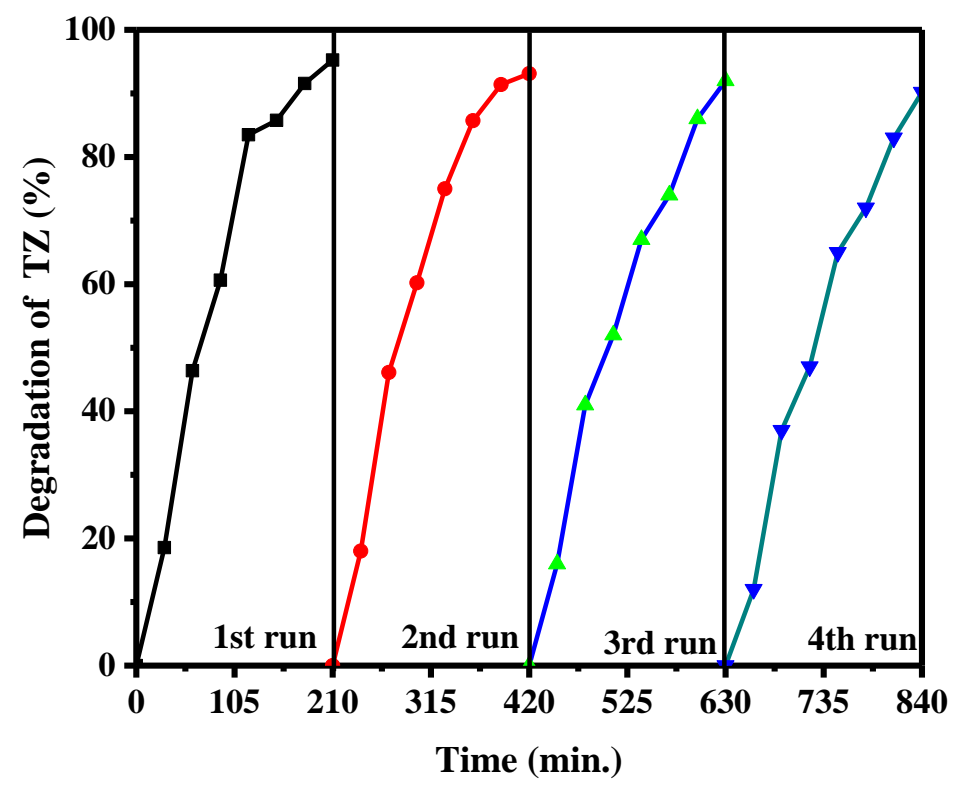

Figure 11. Repetitive photocatalytic degradation of tartrazine over MRGT50 under visible light

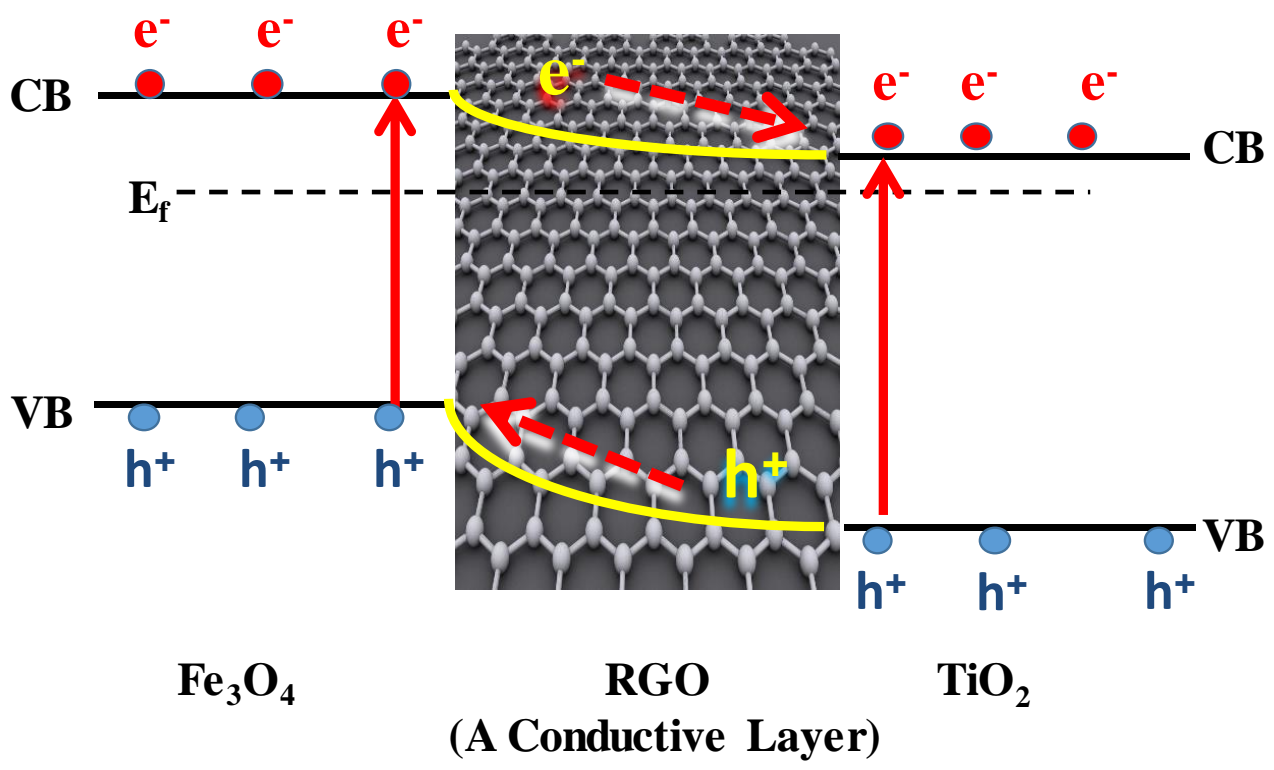

Figure 12. Mechanism of photogenerated charges in MRGT50. 
